\title{
Community-Based Organizations' Role in Ghanaian Agriculture Sector Development: The Case of Ashanti Region
}

\author{
Bismark Yeboah Boasu Kennedy Asenso \\ Department of Social Sciences, S.D.A College of Education, Asokore-Koforidua, Ghana
}

\begin{abstract}
Agriculture is not only the backbone of Ghanaian economy but also conducive to development through livelihood creation and promotion of cooperation among people, particularly those living in the rural communities. CBOs are seen to be indigenous organizations whose roles influence agricultural sector development. Previous studies have shown that many people either unaware or have wrong perception on CBOs' level of performance in achieving agriculture development in Ghana and Ashanti region to be specific. The study therefore examined CBOs' roles in agricultural sector development. Thematic analysis was done from the primary data gathered through semistructured interview, focus group discussions and non-participant observations. It was discovered that CBOs play a pivotal role in information dissemination, education and training, resource mobilization, production and marketing of goods to enhance Ghanaian agriculture sector development. They are however constrained with numerous challenges. The study recommends that NGOs and other stakeholders should also be encouraged to liaise with CBOs and support them to achieve their objectives of ensuring agriculture sector development.
\end{abstract}

Keywords: Community-Based Organizations, Roles, Agriculture Sector Development

DOI: $10.7176 / \mathrm{JCSD} / 57-02$

Publication date:March $31^{\text {st }} 2020$

\subsection{INTRODUCTION}

Ghana's economy is basically agrarian; it is therefore not surprising that agriculture is considered the backbone of the nation. It contributes substantially to government revenue mainly through duties paid on the export of agricultural commodities, especially cocoa; and it has been the major contributor to Ghana's foreign exchange earnings for several years. Until 1992, the sector accounted for the highest proportion of total foreign exchange earned in the country. This role has been performed through exports of agricultural commodities and conservation of foreign exchange by producing import-substituting food and raw materials. Between 1999 and 2002 for example, the agricultural sector contributed $38.5 \%, 35.4 \%, 33.9 \%$, and $35.5 \%$, respectively, to the country's foreign exchange earnings (Asuming-Brempong, 2004). National Development Planning Commission [NDPC] (2009) reports that the Agriculture sector engages about 60 per cent of the country's labour force, contributes 33.6 per cent to the country's GDP and accounts for about 53 per cent of the country's export earnings as of 2008 . Agricultural sector is critical to national food security, and a vital source of raw materials for local agro-based industries (NDPC, 2009: 45); hence its essence in national development since the economy depends on it for growth (Boniface Ablekpe in Daily Graphic, 28/11/05, p.7).

The Agricultural sector in the Ghanaian context encompasses five major sub-sectors, viz: Irrigation, Livestock, Crop, Fisheries and Support Services which include extension, marketing, storage and intersectoral link in processing and feeder roads (Medium Term Agricultural Development Plan: 1991-2000). The aim of the Agricultural sector is to ensure food security and facilitate the production of agricultural raw materials for industry and agricultural commodities for export and the key activities in the sector are food cropping and livestock, cocoa production and marketing, forestry and logging, and fishing. Over the years, various governments have made several efforts to improve the Agricultural sector of the economy. In the 1980s and 1990s, for instance, government policies under the Economic Recovery Programme and related Structural Adjustment Programmes have focused on food security. Since 2001, this has been further buttressed by the emphasis on self-sufficiency in food products. Import substitution has also become an important policy issue in the last couple of years. Today, planting for food and jobs is the policy of the government and for the Agricultural sector development. However, government's budgetary allocation as a percentage of total discretionary budgetary spending has declined and remains woefully inadequate as Ghana's medium and long term development strategies emphasize modernization of agriculture as a basis for industrialization and a driver of accelerated economic growth (Dr Boi Ocansey in The Daily Graphic, 21/07/09 p.17).

Government is constrained by limited budget though, creation of enabling environment for private sector operation is always available to boost the agricultural sector. It is against this background that over the years Civil Society groups, including Community-Based Organizations ( $\mathrm{CBOs}$ ) are called to be part of the process of improving agricultural production, processing, distribution and marketing. This study, therefore, aims at examining the roles of CBOs in agricultural sector development in the Ashanti region of Ghana. 


\subsection{PROBLEM STATEMENT}

The agricultural sector continues to record a low growth rate as compared to the other sectors. It remains not only problematic but also an obstacle to the realization of serious national development. The development of agriculture in Ghana therefore calls for collaborative efforts of all stakeholders, including CBOs. However, many Ghanaians have little or no idea of the kind of activities CBOs are engaged in and their impact in the development circles in general and agricultural development in particular are virtually unknown (Opare, 2007). In its annual progress report in 2009, the NDPC confirmed that Ministry of Food and Agriculture (MoFA) does not receive the needed recognition from key operators in the CBOs and that there are numerous CBOs all over the country without coordination. In view of this, less or no importance is attached to their existence and role in the agricultural sector. There is, therefore, the need to investigate the operations of CBOs and examine their role towards agricultural development in Ghana and Ashanti region in particular by seeking to find answers to the following research questions:

1. What has been the operational environment of CBOs in Ashanti region?

2. What are the key roles CBOs are expected to play in the development of agriculture in Ashanti region?

3. What can be done to improve the CBOs' capacity to develop the agricultural sector in Ashanti region?

\subsection{OBJECTIVES OF THE STUDY}

Generally, the study aims to unveil the pivotal roles of CBOs and specifically hopes to achieve the following:

1. To investigate in the operational structure of CBOs in Ashanti region.

2. To examine the roles of CBOs in the development of agriculture in Ashanti region.

3. To make possible recommendations that would inform policy to improve CBOs' capacity to develop the agricultural sector.

\subsection{CONCEPTUAL FRAMEWORK FOR CBOS' OPERATIONS IN AGRICULTURE SECTOR DEVELOPMENT}

The success of CBOs depends heavily on developed organizational and communication skills, including the development of both social and human capital through research, extension and education programmes aimed at improving the farmers' technical and managerial capacity (Leslie, 2005). The Social-capital theory lays emphasis on trust, team-work, building of relationship and legitimate power for community development (Morrison \& Ramsey, 2018), which could be achieved by creating the awareness through effective communication (Ibitayo, 2006). Effective communication raises the awareness of CBOs and intensifies better education to ensuring the realization and sustainability of their operations in the agriculture sector. CBOs performance in agriculture sector depends on intervention approach and a framework or model. After reviewing many models, the Efficacy Outcome Expectancy and the Spiral of Silence Theory of Opinion Formulation Models which Boasu (2011) found to be related to the Social-capital theory were adapted for the study.

The proponents of the Efficacy - Outcome Expectancy model believe that organizational behaviour and change are motivated in the direction of achieving valued rewards (March and Simons, 1989). The model suggests that organizational or group pressure constitutes a source of motivation for behaviour and change. According to Katz and Kahn (1978), there are various sources of motivation and two of them are: Outcome Expectancy (the believe that behaving in a certain way will produce anticipated benefits); and Efficacy Expectancy (the conviction that one can successfully execute the behaviour required to produce those outcomes). Adapting the model to this study will mean that the low development in the Agriculture sector is due to the individual and organizational behaviour or attitudes toward the sector. If this assertion were true, it may be related to the lack of incentives (motivation), both immediate and long term, to induce huge number of individuals and organization or groups' active participation in farming. Although this model contextually seems too narrow in its assumption - by only emphasis the need for incentives (which may be only one of the factors affecting efficiency of the Agriculture sector in Ghana), it is still useful for the study especially when it combines with other models. In this case, incentive packages such as frequent Extension Services, Loan or grant facilities, ready market and 'Best CBOs' Award' could be instituted to create favourable competition among the CBOs and entice other individuals and groups to form effective and efficient CBOs towards agriculture development.

The Spiral of Silence Theory of Opinion Formulation model, on the hand, explains the effects of mass media in communication. The model has it that the more frequently the dominant or majority opinions is disseminated by the mass media, the more likely it is that individuals with central opinions will remain silent; accelerating the effects of the mass media (the spiraling process) to be specific. The proponents of this theory asserts that for a new minority opinion to be adopted, the ideal condition is for the majority opinion to remain silent while the minority opinion receives more public awareness via the mass media. Adopting the model to this study, the CBOs mainly into agriculture activities are considered as the 'minority opinion' and those for welfare and fashion as the 'majority 
opinion'. In this case, for CBOs to win public confidence in agriculture development and achieve effective and efficient performance of their roles, there is the need for intensive public education, through mass media, thereby informing the public to withdraw slowly from the over reliance on the CBOs for self-gain and fashion and focus diligently on development issues in general and agriculture development in particular. Again, if organizational and group pressures are to bring changes, then strategies such as intensifying public awareness and educational programmes may help improve the status quo. Moreover, if members of CBOs are given the needed education in general management; organization and technical issues; research and self-help initiative; and networking and advocacy, they will be equipped with many skills to play their role in the development of agriculture sector.

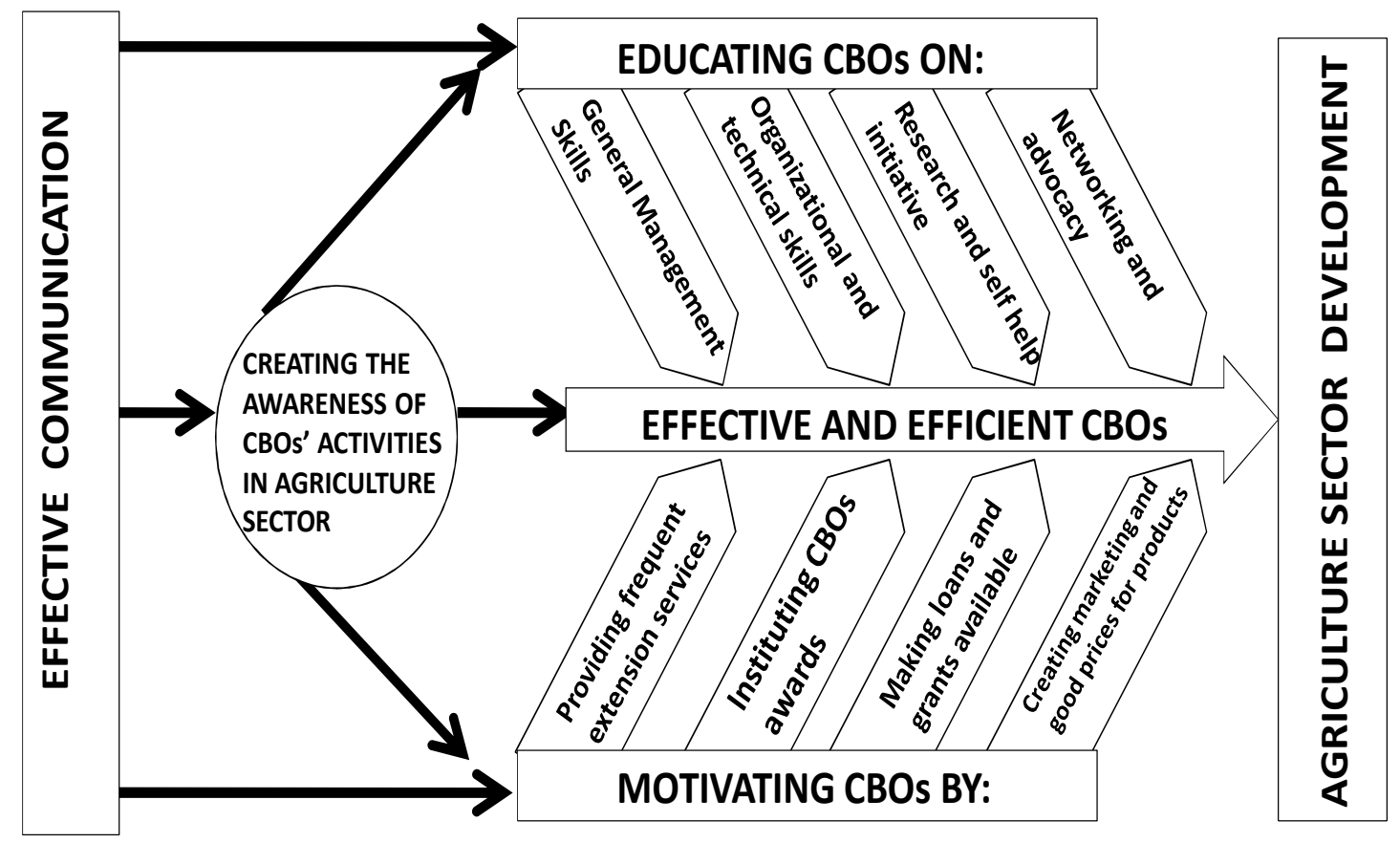

Figure 1.1: The Framework for CBOs' operations in Agriculture Development

Source: Boasu (2011)

The framework indicates that agriculture development depends on the CBOs' effectiveness and efficiency which are enhanced by three main variables: effective communication, education and motivation. Communication is a two-way discourse that harmonizes differing views in decision-making (van der Vegt, 2017). Effective communication thus aims to correct misunderstandings in line with a central ideological framing (Árvai, 2014) and a major way of helping individuals to identify, comprehend, and act promptly to ensure effectiveness and efficiency (Lazrus, Morss, Demuth, Lazo \& Bostrom, 2016).

From the framework, effective communication is not only a catalyst for educating CBOs' members but also a source of motivation to their operations in the agriculture sector. It also helps raise the awareness of both the public and the policy-makers on the effective and efficient roles that CBOs' play in the Agriculture sector. Besides, stakeholders - government, NGOs, and private individuals could better understand CBOs' problems thereby paying necessary attention to their demands including the provision of frequent extension services, awards, loans and grants, and good market to enhance their operations. Furtherance, authorities are able to educate members in CBOs on general management skills; organizational and technical skills; research and self-help initiative; and networking and advocacy skills. This motivates the members in CBOs and commits them to offer their best. The combination of these three variables makes the CBOs effective and efficient in their roles and/or activities in the agriculture sector which eventually brings the necessary development in the sector.

\subsection{MATERIALS AND METHODS}

Ashanti is one of the regions of Ghana that is endowed with significant natural and human resources that can be exploited for the Agricultural development of the nation. The region is centrally located in Ghana. Specifically it lies nearly between Latitude $5^{\circ} 50^{\prime}-5^{\circ} 70^{\prime}$ North and Longitude $0^{\circ} 15^{\prime}-2^{\circ} 20^{\prime}$ West. The total area of the region is 24,390 sq. $\mathrm{km}$ representing $10.2 \%$ of the total land area of Ghana. The region is gifted with good drainage, relief, geology, vegetation and soils suitable for agricultural activities. The region also has a climate that is conducive for agricultural activities. For example, the region experiences two rainy seasons in a year with average annual rainfall 
of about $166.7 \mathrm{~cm}$; the average temperature is over $27^{\circ} \mathrm{C}$ in the forest zone and $29^{\circ} \mathrm{C}$ on the northern fringes of the forest zone; and the humidity is relatively high averaging about $85 \%$ and $65 \%$ in the forest and savanna belt respectively. The region also has a large proportion of population ready to fill job vacancies in the agricultural sector. An investigation into the number of CBOs and the activities they perform in the region revealed that there are 166 registered CBOs representing $11.2 \%$ of the national total of 1,487 . Out of this, 49 CBOs representing $29.5 \%$ operates in agriculture and food security activities (MoF A, 2009).

The researchers made use of qualitative description within the interpretative paradigm which according to Polit and Beck (2004) makes an ontological assumption that reality is multiple and subjective, and mentally constructed by individuals. Descriptive research design which, according to Gay (2009), involves collecting data in order to answer research questions concerning the current status of the subject of the study was appropriate because the researchers made use of the data collected to answer the questions raised in this study. The researchers also made extensive use of literature review on the role of CBOs in agricultural development. In addition, interviews and focused grouped discussions were used as major investigative tools in soliciting the people's opinions on the issues raised in this study. That is, data were collected from CBOs' leaders, who were believed to have in-depth knowledge of the operations of their organizations, through semi- structured interview. To ascertain the credibility of the study, a non-participant observation and an hour of focused grouped discussion involving 610 people (consisting of two members sampled randomly from each selected CBO) was conducted in each of the selected districts as a means of cross-validating the data obtained from the leaders.

Polit, Beck and Hungler (2001) postulate that sample size in qualitative studies tends to be small because the strategies as well as methods for data collection and analysis are very time consuming, and the amount of data collection can be considerable. Minerva (1994) also argues that to ensure the representativeness of a homogeneous population in a research, a sample size of $50 \%$ is desirous. Consequently, twenty-five CBOs out of 49 CBOs whose activities were skewed towards food security and in favour of agricultural development in the region were purposively selected from three assemblies (i.e. Obuasi Municipal, Sekyere South and Kwabre East districts) for the study. The sample size was carefully chosen because the researchers believed that by observing the characteristics of the CBOs, inferences could be made to represent the behaviour and characteristics of the total population of the study area. This $50 \%$ of the total population of CBOs enabled the research findings to be more representative of the actual situation on the ground.

Data for the study was obtained from both primary and secondary sources. Under primary source, emphasis was on the collection of data directly from field surveys via interviews and focused group discussions. The primary data provided reliable and accurate firsthand information relevant to the study about the activities of CBOs in relation to agricultural development. In the secondary source, data collection came from documents and internet. The aim of the collection of secondary data was to gather necessary information to guide the conduct of the study in order to confirm or reject the primary data.

Interpretative and descriptive approach were adopted to analyse the data based on the argument put forward by Mays and Pope (1996) that a qualitative researcher will need to ensure that data analysis enables the meaning of the phenomenon to be understood while maintaining the individuality of each participant's experience. Miles and Huberman (1994) established that qualitative analysis involves familiarization with, and identification of themes. It is also confirmed that the best approach in data analysis in qualitative research is to tape record the interviews and transcribe them (Robson, 2002). All the interviews were therefore tape-recorded and transcribed verbatim from the local language to English by the researchers to enhance the credibility of the study.

\subsection{FINDINGS AND DISCUSSIONS \\ 1.6.1 Respondents' Personal Information}

The information about respondents was analyzed in terms of sex, age, educational level and the number of years they held leadership positions in the organizations. It came out that out of the 25 respondents, fifteen (i.e. $60 \%$ ) were males. In terms of age, only one respondent was below 30 years. The majority of CBO leaders (i.e. 64\%) were between 46 and 55 years. The level of education one attains tells the capabilities of the person in terms of thinking, managerial and leadership skills to move an organization forward. It was realized that only one (that is $4 \%$ ) had attained tertiary education level, majority of them (that is $76 \%$ ) had their education up to basic level. This means that the capability of a leader to manage and move CBOs forward does not depend on the level of education one attains. This is an indication that the managerial and leadership skills which CBOs' leaders acquire to move their organizations forward could be obtained through other means such as hand-on-job training. With regard to experience, It was found that only 36 per cent had held leadership position for less than three years. The remaining 64 per cent had held their positions for more than three years. Since majority (i.e. 64\%) had held the leadership position in their organizations for four or more years, they were more experienced and knowledgeable to lead the organization.

\subsubsection{The Roles of CBOs in the Development of the Agricultural sector}

$\mathrm{CBOs}$ are expected to play specific roles including production, information dissemination, education and training 
and marketing of products in the agricultural sector to ensure development. Since objective(s) of an organization determines its role, the researchers examined the roles of CBOs based on their set objectives. It was realized that CBOs' objectives were reflection of their roles and included: putting resources together for development; producing in large quantity for sale; receiving training and retraining people on modern technology in farming, among others. Some of these roles, especially the production and marketing have also been established by Kohls (1986). This also confirms Kaplan's (1996) assertion that CBOs support their members to create market for themselves, aid them to be educated and trained on modern technology in production and above all help them to transform their socio-economic situations.

It also came out that CBOs provide education and training to community members when 84 per cent of the respondents confirmed it. This indicates that information dissemination and application of modern technology in agricultural sector could be entrusted to $\mathrm{CBO}$ because they are able to provide education and training to community members. Additionally, all the 25 leaders declared that their organizations gave opportunities to the members in diverse ways including seeking for loans, provision of training in modern technology, marketing of their produce and so on. According to Kaplan (1996), CBOs assist their members to create market for themselves, help them to be educated and trained in modern technology in production and above all aid them to transform their socio-economic situations. This assertion agrees with what the study revealed and it is an indication that, besides agricultural development, CBOs could also help raise the standard of living of the members if they are empowered to do so by external sources.

The views of the participants for the focused grouped discussions on whether or not the CBOs contribute to the development of the agricultural sector were solicited. The participants unanimously admitted that their organizations really play major roles in the development of agriculture but in diverse ways. Touching on the type of roles the CBOs play, a man said: 'My organization cultivates vegetable farms in large scale for commercial purpose' (man, FGDs). Another declared: 'My organization disseminates all sorts of information and technology from the MoFA to both members and non-member, especially those into agriculture activities (Man, FGDs). And finally, a woman made a confirmation by saying that: 'My organization processes oil palm for sale. This revelation is an indication that CBOs are indispensable in agricultural development since they served as contact groups for production, processing and marketing of agriculture products, as well as information and technology dissemination in various communities. With regard to the level of performance of CBOs in agricultural development, a man said: 'CBOs are effective in their performances' (Man, FGDs). This assertion was however contested when almost all the participants supported the declaration from a woman that: 'CBOs are ineffective in their attempts to develop the agricultural sector because of numerous challenges we encounter in the course of our operations' (Woman, $F G D s)$. This indicates that a lot of CBOs were not performing as expected in the various districts.

\subsection{CONCLUSION AND POLICY RECOMMENDATIONS}

$\mathrm{CBOs}$ are seen to be indigenous organizations which play major role in agricultural development in the Ashanti region of Ghana. CBOs contribute towards agricultural development in the form of information dissemination, resource mobilization, production and marketing of agricultural goods as well as provision of education and training to the community members. These roles have reinforced the development of the agricultural sector in the region. However, the various challenges that CBOs encounter in their operations in the study area impede their capabilities of development. This situation affects the effective and efficient performance of CBOs in the development of the agriculture sector in the region.

It is recommended that the Non-Governmental Organizations, especially those whose activities contribute towards agriculture development, should be encouraged to liaise with the CBOs and support them to achieve their objectives in the development of the agriculture sector. Again, MoFA and other stakeholders should also give intensive and frequent education and training to the CBOs members to enable them build their requisite capacity in records keeping. This will offer an opportunity for MoFA to do better assessment of the CBOs' contributions to agriculture sector. Above all, policy-makers could apply the framework from this study to enhance the level of performance of CBOs in achieving agriculture development in the study area and even beyond.

\section{REFERENCES}

1. Asuming-Brempong, S. (2004): Exchange Rate Liberalization and Input-Subsidy Removal. In Issues in African rural Development 2. S. A. Berth (Ed.). Winrock International inst.For Rural Development. USA.

2. Árvai, J. (2014). "The End of Risk Communication as We Know It.” Journal of Risk Research 17 (10): 12451249.

3. Boasu, B.Y. (2011). Assessing the Role of Community-Based Organizations in Agriculture Development in the Ashanti Region. A thesis submitted to Kwame University of Science and Technology, Kumasi, in partial fulfillment of the requirement for the award of MSc. Development Policy and Planning degree (Unpublished).

4. Boi Ocansey (2009). "Call for National Agric Fund Bill”. The Daily Graphic, July 21.

5. Boniface Ablekpe (2005): 'Agriculture: Key to poverty reduction'. The Daily Graphic, November 28. 
6. Gay, I. R. (2009): Educational Research, Competences for Analysis and Applications.

7. Ibitayo, O. O. (2006). Egyptian farmers' attitudes and behaviours regarding agriculture pesticides: implications for pesticide risk communication. Risk Analysis: An International Journal, 26(4), 989-995.

8. Kaplan A. (1996): The Development Practitioners' Handbook, Pluto Press, London, UK and Chicago, IL.

9. Katz D. and Kaln R. (1978): The Social Psychology of Organization, New York, Willy.

10. Kohls, R. H. (1986): Marketing of Agricultural products $-7^{\text {th }}$ Edition, Macmillan, N. Y.

11. Lazrus, H., Morss, R.E., Demuth, J. L., Lazo, J.K. and Bostrom, A. (2016). "Know What to Do If You Encounter a Flash Flood": Mental Models Analysis for Improving Flash Flood Risk Communication and Public Decision Making. Risk Analysis, Vol. 36, No. 2, DOI: 10.1111/risa.12480.

12. Leslie D. (2005): Good Growing - Why Organic Agriculture Works advocates "a new certification label the Fair Share".

13. Mays, N. and Pope, C. (1996): Qualitative Research in Healthcare. London, BMJ publication.

14. March J. and Simon H. (1989): Population - An Introducction to Concepts and Issues, Wadsnorth, Inc. U.S.A.

15. Medium Term Agricultural Development Plan, 1991 - 2000, vol. I

16. Miles, M.B. and Huberman, A.M. (1994): Qualitative Data Analysis; an expanded soucebook (2 $2^{\text {nd }}$ Ed), London, Sage.

17. Minerva, C.C. (1994): Popularizing Research; A Manual for Facilitating Participatory Action Research in the Community. Centre for Community Services (CCS), Ateneo de Minerva University, Philippine.

18. MoFA (2009): Directorate of NGOs and CBOs

19. Morrison, C. \& Ramsey, E. (2018). Power to the people: Developing networks through rural community energy Schemes. Journal of Rural Studies 1, 0743-0167

20. National Development and Planning Commission (2009): Implementation of the Growth and Poverty Reduction Strategy 2006 - 2009; 2008 Annual Progress Report.

21. Opare, S. (2007): Strengthening community-based organizations for the challenges of rural development. Community Development Journal 2007 42(2):251-264.

22. Polit, D.F., Beck, C.T. and Hungler, B.P. (2001): Nursing Research; Methods, Appraisal and Utilization Principle $\left(5^{\text {th }} \mathrm{Ed}\right)$, Philadelphia, Lipincott.

23. Polit, D.F. and Beck, C.T. (2004): Nursing Research; Methods, Appraisal and Utilization Principle (6 ${ }^{\text {th }}$ Ed), Philadelphia, Lipincott.

24. Robson, C. (2002): Real World Reseach, $2^{\text {nd }}$ Edition; Oxford, Blackwell.

25. van der Vegt, R.G. (2017). A literature review on the relationship between risk governance and public engagement in relation to complex environmental issues, Journal of Risk Research, DOI: 10.1080/13669877.2017.1351466. 